\title{
Dynamic Scaling Exponents of Copper Electrodeposits from Scanning Force Microscopy Imaging. Influence of a Thiourea Additive on the Kinetics of Roughening and Brightening
}

\author{
S. Mendez ${ }^{\dagger}$ G. Andreasen, P. Schilardi, M. Figueroa, ${ }^{\dagger}$ L. Vázquez,,$^{\ddagger}$ \\ R. C. Salvarezza, and A. J. Arvia* \\ Instituto de Investigaciones Fisicoquímicas Teóricas y Aplicadas (INIFTA), Sucursal 4 , \\ Casilla de Correo 16, (1900) La Plata, Argentina
}

Received April 8, 1997. In Final Form: February 9, 1998

\begin{abstract}
Changes in the topography of $\mathrm{Cu}$ electrodeposits grown on polycrystalline $\mathrm{Cu}$ substrates at low constant current density from still aqueous concentrated $\mathrm{CuSO}_{4}+\mathrm{H}_{2} \mathrm{SO}_{4}$ solutions, at $298 \mathrm{~K}$, were studied by scanning force microscopy (SFM) at different scale lengths $(L)$ from the nanometer level upward. The dynamic scaling theory applied to SFM images leads to exponents $\alpha=0.87 \pm 0.06$ and $\beta=0.63 \pm 0.08$, which are consistent with an interface growing under an unstable regime. For similar conditions, the addition of 1,3-diethyl-2-thiourea reduces the average crystal size $\left(\left\langle\mathrm{d}_{\mathrm{s}}\right\rangle\right)$ of electrodeposits leading to scaling exponents $\alpha=0.86 \pm 0.06$ and $\beta=0.24 \pm 0.05$ for $L<\left\langle\mathrm{d}_{\mathrm{s}}\right\rangle$ and a logarithmic dependence for the spatial and temporal evolution of the interface for $L>3 \mu \mathrm{m}$ and $t \rightarrow 0$. In an additive-free plating bath, the unstable growth regime appears to be originated by enhanced electrodeposition at protrusions due to curvature effects and further sustained by the electric and concentration fields built up around the growing deposit. The presence of the additive hinders the development of instabilities driving the evolution of the growing interface to that predicted by the Edwards-Wilkinson growth model on the asymptotic limit.
\end{abstract}

\section{Introduction}

1.1. Development of a Mobile Interface. Physical processes involved in either particle aggregation to or detachment from a solid substrate play a key role in determining the topography of the solid and its dynamic behavior. ${ }^{1}$ Typical examples of these processes are the growth of a solid metal from either vapor or electrochemical deposition and the attack of a solid phase by an aggressive environment. The characteristics of the interface motion depend on the substrate nature, the growth rate, the environment composition, and temperature. ${ }^{1-4}$

When the initial substrate is a smooth flat solid over which the deposition of a solid takes place, the topography (herafter denoted the mobile interface) usually becomes rough on increasing the electrodeposition time. When the rougheness caused by the stochastic noise of attaching particles is compensated by the smoothness produced by surface relaxation, a statistically steady state for the mobile interface can be reached. On the other hand, when the roughness increases continuously with time, an unstable interface front develops. Both situations have been found for a number of systems such as vapor metal deposition $^{5}$ and metal electrodissolution in aggressive media. ${ }^{6}$

In general, at low deposition rates, the solid growth would be dominated by local effects leading to a deposit with a self-affine fractal surface, ${ }^{7,8}$ whereas at high

† Facultad de Química, Departamento de Química Inorgánica, Pontificia Universidad Católica de Chile.

${ }^{\ddagger}$ Instituto de Ciencia de Materiales, CSIC, Madrid, Spain.

(1) Stanley, E.; Barabasi, A. Fractal Concepts in Surface Growth; Cambridge University Press: New York, 1994.

(2) Meakin, P. Phys. Rep. 1993, 235, 191.

(3) Salvarezza, R. C.; Arvia, A. J. In Modern Aspects of Electrochemistry; Conway, B. E., Bockris J. O'M., White, R. E., Eds.; Plenum Press: New York, 1996; Vol. 28, Chapter 5, p 289.

(4) Halpin-Healey, T.; Zhang, I. C. Phys. Rep. 1995, 254, 215. deposition rates nonlocal effects such as either shadowing or the presence of electric and concentration fields would assist the development of branched patterns with a selfsimilar mass and/or surface., ${ }^{8,9}$

1.2. Outline of the Dynamic Scaling Theory. In general, the kinetics of phase growth and, correspondingly, the dynamics of the mobile interface can be studied by applying the dynamic scaling theory ${ }^{10}$ to surface profiles on both temporal and spatial scales. According to this theory, for a surface profile of length $L$ consisting of $N$ points, the theory predicts that $W(L, t)$, the mobile interface width, involving an average profile height $\langle h\rangle$, scales as ${ }^{10}$

$$
W(L, t) \propto L^{\alpha} f\left(t / L^{\bar{Z}}\right)
$$

where $W(L, t)$ is defined by

$$
W(L, t)=\left[1 / N \sum_{i}\left[h\left(\mathbf{x}_{i}\right)-\langle h\rangle\right]^{2}\right]^{1 / 2}
$$

and $h\left(\mathrm{x}_{i}\right)$ is the deposit height measured along the $\mathrm{x}$-direction at the point $\mathrm{x}_{i}$, and $z=\alpha / \beta$, where $z, \beta$, and $\alpha$ are the dynamic, the growth, and the roughness exponent, respectively. ${ }^{1}$ The reciprocal of $z$ is also referred to as the coarsening exponent. Furthermore, in eq $1, f\left(t / L^{z}\right)$ has the following properties: $f\left(t / L^{z}\right)=$ constant for $t / L^{z} \rightarrow \infty$,

(5) Salvarezza, R. C.; Vázquez, L.; Herrasti, P.; Ocón, P.; Vara, J. M.; Arvia, A. J. Europhys. Lett. 1992, 20, 727.

(6) Vela, M. E.; Andreasen, G.; Salvarezza, R. C.; Arvia, A. J. Phys. Rev. B 1996, 53, 10217.

(7) Iwamoto, A.; Yoshinobu, T.; Iwasaki, H. Phys. Rev. Lett. 1994, 72, 4025 .

(8) Kahanda, G. L. M. K. S.; Zou, X.; Farrell, R.; Wong, P. Phys. Rev. Lett. 1992, 68, 3741. Pastor, J. M.; Rubio, M. A.; Phys. Rev. Lett. 1996 $76,1848$.

(9) Meakin, P. In The Fractal Approach to the Heterogeneous Chemistry, Avnir, D., Ed.; J. Wiley: New York, 1989; p 131.

(10) Family, F. Physica A 1990, 168, 561 and references therein. 
and $f\left(t / L^{z}\right)=\left(t / L^{z}\right)^{\beta}$ for $t / L^{z} \rightarrow 0$. Therefore, eq 1 comprises two limiting cases, namely, for $t / L^{z} \rightarrow \infty$

$$
W(L) \propto L^{\alpha}
$$

and for $t / L^{z} \rightarrow 0$

$$
W(t) \propto t^{\beta}
$$

Accordingly, the value of $\alpha, \beta$, and $z$ can be derived from $\log$ vs $\log$ plots of eqs 3 and 4 , respectively. Reliable data for those exponents can be derived from this procedure, when scaling is made over a wide length and time range.

The dynamic scaling analysis has been utilized to follow the behavior of mobile interfaces generated by both atomistic and continuous models. ${ }^{1}$ Thus, simple aggregation models such as the ballistic deposition ${ }^{11}$ and the Eden models ${ }^{12}$ including lateral growth, which are well described by the Kardar, Parisi, and Zhang (KPZ) stochastic equation, ${ }^{13}$ lead to $\alpha \cong 0.4$ and $\beta \cong 0.25$ for the threedimensional (3D) space. On the other hand, when restricted surface diffusion is included, the interface exhibits $0.66 \leq \alpha \leq 1$ and values of $\beta$ in the range 0.20 $\leq \beta \leq 0.25 .{ }^{14,15}$ A crossover in the value of $\beta$ from 0.25 to 1 has been also reported when a complete equation for surface diffusion is considered. ${ }^{16}$ Finally, when complete surface relaxation is permitted, such as in the random deposition with surface relaxation model, ${ }^{1}$ the interface evolution fits the Edwards-Wilkinson (EW) stochastic equation $^{17}$ leading to $W \propto(\log L)^{0.5}$ and $W \propto(\log t)^{0.5}$ dependences, for $t \rightarrow 0$ and $L \rightarrow 0$. On the other hand, for $t \rightarrow \infty$ and $L \rightarrow \infty$, the EW equation leads to $\alpha=0$ and $\beta$ $=0$.

When the preceding analysis is applied to either an unstable or a marginally stable interface, it results in $\beta$ $>0.5$ and the dynamic scaling approach breakdown. ${ }^{1}$ In this case, only an effective value of $\alpha$ can be derived from eq 3 .

The dynamic scaling theory has recently been applied to the analysis of topographic profiles resulting from scanning tunneling microscopy (STM) and scanning force microscopy (SFM) imaging. ${ }^{5,7,18}$ In these cases, from both SFM and STM topographic profiles, eqs $1-4$ were applied to the mobile interface width determined from either SFM or STM by setting $W(L, t)=W_{\mathrm{SFM}}$ and $W(L, t)=W_{\mathrm{STM}}$, respectively.

It should be noted that for computer-simulated fractals, data covering 4 to 5 orders of magnitude are required for logarithmic fitting. For experimental systems, however, this goal is less ambitious owing to the existence of inner and outer cutoffs, and data covering 1 or 2 decades on time and length scales have been considered acceptable. ${ }^{1,18}$

1.3. Previous Results on Cu Deposit Growth. In recent years the growth modes of metal electrodeposition under nonequilibrium growth conditions have been investigated using both $3 \mathrm{D}$ and quasi-2D electrochemical cells of different geometries with the main purpose of

(11) Meakin, P.; Ramanlal, P.; Sander, L. M.; Ball, R. C. Phys. Rev. A 1986, 34, 509 .

(12) Eden, M. Proceeding of the 4th Berkeley Symposium on Mathematical Statics and Probability; Neyman, F., Ed.; University of California Press: Berkeley, 1961; Vol. 4.

(13) Kardar, M.; Parisi, G.; Zhang, Y. C. Phys. Rev. Lett. 1986, 56, 889 .

(14) Wolf, D.; Villain, J. Europhys. Lett. 1990, 13, 389. Villain, J. J. Phys. I 1992, 1, 19. Das Sarma, S.; Tamborenea, P. Phys. Rev. Lett. 1991, 66, 325. Lai, Z. W.; Das Sarma, S. Phys. Rev. Lett. 1991, 66, 2348. (15) Siegert, M.; Plischke, M. Phys. Rev. Lett. 1994, 73, 1517.

(16) Family, F. In Fractals in the Nature and Applied Sciences; North-Holland: Amsterdam, 1994; p 1.

(17) Edwards, S. F.; Wilkinson, D. R. Proc. R. Soc. London, Sect. A 1982, 381, 17.

(18) Krim, J.; Palasantzas, G. Int. J. Modern Phys., B 1995, 9, 599. establishing quantitative relationships between the surface topology, including growth mode transitions and different variables such as those related to the flux rate of depositing species, and the various mass transport contributions which have been controlled through the solution composition and hydrodynamic flow. ${ }^{19}$ In general, for $\mathrm{Cu}$ electrodeposition at low current density compact deposits are formed, ${ }^{7}$ whereas at high current densities the formation of branched deposits is favored. ${ }^{8}$ At a constant temperature, this tendency has been observed irrespective of the cell design and solution composition.

Previous studies on interface motion at 3D Cu deposits produced at low rates have reported $\alpha \cong 1$, irrespective of the deposition technique. ${ }^{20-22}$ This value of $\alpha$ is close to that predicted by growth models incorporating surface diffusion as referred to in section $1.2 .{ }^{14-17}$ In contrast to $\alpha$, the experimental values of $\beta$ are widely scattered. Thus, $\beta=0.60$ has been found for chemical vapor deposited $\mathrm{Cu}$ films, ${ }^{20}$ whereas values in the range $0.26<\beta<0.56$ have been reported for $\mathrm{Cu}$ films grown by molecular beam epitaxy. ${ }^{21}$ Otherwise, $\beta=0.45^{7}$ and $\beta=0.11^{22}$ have been found for $\mathrm{Cu}$ electrodeposits. These figures are far from the expectations of simple models including surface diffusion. ${ }^{14-17}$

Values of $\beta>0.25$ for $\mathrm{Cu}$ deposits have been tentatively explained either by considering the influence of Laplacian fields on the interface motion even at low deposition rates $^{7,20}$ or by the occurrence of an energy barrier at step edges $^{21}$ or by shadowing effects among growing crystals. ${ }^{1}$ Therefore, there is an open question about the origin of the unstable growth regime, and further work, particularly concerning the evolution of $\beta$ under different phase growth conditions, is certainly needed.

A possible way to contribute to understand the mobile interface behavior would be to compare $\mathrm{Cu}$ electrodeposition from additive-free and additive-containing acid plating baths. It is well-known that the presence of certain organic additives in acid $\mathrm{Cu}$ plating baths, particularly thiourea derivatives and thiourea itself, produces a decrease in roughness, suppressing disordered growth and promoting leveling and brightening of $\mathrm{Cu}$ electrodeposits.

1.4. Influence of Additives on $\mathrm{Cu}$ Electrodeposition from Acid Baths. Extensive work has been carried out on the kinetics of both $\mathrm{Cu}$ electrodeposition on different substrates and $\mathrm{Cu}$ anodic stripping in additive-free and additive-containing acid plating baths with particular attention to nucleation and growth processes. ${ }^{28-32}$ Results of such work have been extensively reviewed. ${ }^{33-35}$

(19) Matshushita, M. In The Fractal Approach to the Heterogeneous Chemistry, Avnir, D., Ed.; J. Wiley: New York, 1989; p 161 and references therein.

(20) Vázquez, L.; Albella, J. M.; Salvarezza, R. C.; Arvia, A. J.; Levy, R. A.; Perese, D. Appl. Phys. Lett. 1996, 68, 1285.

(21) Ernst, H. J.; Fabre, F.; Folkerts, R.; Lapujoulade, J. Phys. Rev. Lett. 1994, 72, 112.

(22) Schmidt, W. U.; Alkire, R. C.; Gewirth, A. A.; J. Electrochem. Soc. 1996, 143, 3122 .

(23) Levich, V. G. Physicochemical Hydrodynamics; Prentice-Hall: Englewood Cliff, NJ, 1962.

(24) Bertocci, U.; Turner, D. R. In Encyclopedia of Electrochemistry of the Elements; Bard, A. J., Ed.; M. Dekker: New York, 1976; Vol. 2, p 383.

(25) Hine, F. Electrode Processes and Electrochemical Engineering, Plenum Press: New York, 1985.

(26) Smyrl, W. H. In Comprehensive Treatise of Electrochemistry, Bockris, J. O’M., Conway, B. E., Yaeger, E., White, R. E., Eds.; Plenum Press: New York, 1981; Vol. 4, p 97

(27) Bockris, J. O’M.; Reddy, A. K. N. Modern Electrochemistry; Macdonald: London, 1970; Vol. 2, p 1202.

(28) De Agostini, A.; Schmidt, E. Electrochim. Acta 1989, 34, 1243.

(29) White, J. R. J. Appl. Electrochem. 1987, 17, 977.

(30) Burrows, I. R.; Harrison J. A.; Thompson, J. J. Electroanal. Chem. 1975, 51, 241. 
The presence of small amounts of adsorption additives in the $\mathrm{Cu}$ acid plating bath results in remarkable changes in the quality of the deposit. These additives, acting as levelers and brighteners, ${ }^{36,37}$ change the kinetics of nucleation and growth of $\mathrm{Cu}$ in a number of metallic substrates. ${ }^{32,38-40}$ For instance, for $\mathrm{Cu}$ electrodeposition on Pt and W, the influence of additives manifests itself at the initial electrodeposition stage, particularly by decreasing the nucleation rate, ${ }^{41,42}$ changing nucleation from instantaneous to progressive,${ }^{43}$ and reducing the number of active sites in the substrate. Thiourea and related compounds, which are frequently used as additives for $\mathrm{Cu}$ plating in acid baths, ${ }^{44-47}$ increase, however, the number of nuclei for $\mathrm{Cu}$ electrodeposition on $\mathrm{Au}(111)$ by changing the characteristics of the substrate, as concluded from STM imaging, ${ }^{48}$ and reducing the surface mobility of $\mathrm{Cu}$ adatoms. ${ }^{22}$ Generally, the morphology, size, and amount of crystallites produced at the early stages of metal electrodeposition depend on the initial additive/metal ion concentration ratio and applied potential. ${ }^{49}$

Unfortunately, from results available at present, it is not possible to draw an unambiguous conclusion about the actual role of the additive in suppressing unstable growth, as the origin of the unstable interface growth regime remains obscure. Furthermore, data on nucleation and growth of $\mathrm{Cu}$ electrodeposits obtained at high cathodic overpotential can be interpreted with the 3D nucleation theory, but recent in situ AFM data from $\mathrm{Cu}$ deposits have shown that a more detailed theory is required, particularly to account for results obtained at low cathodic overpotentials. ${ }^{50,51}$

1.5. Main Purpose of this Work. This work attempts to determine the origin of the unstable interface growth regime in $\mathrm{Cu}$ electrodeposition at a relatively low current density and the role played by the presence of organic additives in the plating bath. For this purpose, the evolution of the topography of $\mathrm{Cu}$ electrodeposits produced from aqueous $\mathrm{CuSO}_{4}+\mathrm{H}_{2} \mathrm{SO}_{4}$ solutions in the absence and in

(31) Pletcher, D.; Whyte, I.; Walsh, F. C.; Millington, J. P. J. Appl. Electrochem. 1991, 21, 659.

(32) Farndon, E. E.; Walsh, F. C.; Campbell, S. A. J. Appl. Electrochem. 1995, 25,574 .

(33) Damaskin, B. B.; Petrii, O. A.; Batrakov, V. V. Adsorption of Organic Compounds on Electrodes; Plenum Press: New York, 1971.

(34) Damaskin, B. B.; Kazarinov, V. E. In Comprehensive Treatise of Electrochemistry; Bockris, J. O'M. Conway, B. E., Yeager, E., Eds.; Plenum Press: New York, 1980; Vol. 1, Chapter 8, p 353.

(35) Zukauskaite, N.; Malinauskas, A. Elektrokhimiya 1988, 24, 1567.

(36) Plieth, W. Electrochim. Acta 1992, 37, 2115.

(37) Suarez, D. F.; Olson, F. A. J. Appl. Electrochem. 1992, 22, 1002.

(38) Armstrong, M. J.; Muller, R. H. J. Electrochem. Soc. 1991, 138 , 2303.

(39) Turner, D. R.; Johnson, G. R. J. Electrochem. Soc. 1962, 109, 798.

(40) Ke, B.; Hoekstra, J. J.; Sissons, T.; Trivich, D. J. Electrochem. Soc. 1993, 106, 382.

(41) Michailova, E.; Vitanova, I.; Stoychev, D.; Milchev, A. Electrochim. Acta 1993, 38, 2455.

(42) Peykova, M.; Michailova, E.; Stoychev, D.; Milchev, A. Electrochim. Acta 1995, 40, 2595.

(43) Fabricius, G.; Kontturi, K.; Sundholm, G. Electrochim. Acta 1994 39, 2353.

(44) Ratajczak, H. M.; Pajdowski, L.; Ostern, M. Electrochim. Acta 1975, 20, 431.

(45) Fischer, H. Elektrolysche Abscheidung und Elektrokrystallisation von Metallen; Springer: Berlin, 1954.

(46) Reid, J. D.; David, A. P. J. Electrochem. Soc. 1987, 134, 1389 (47) Fabricius, G.; Konturi, K.; Sundholm, G. Electrochim. Acta 1994 39, 2353.

(48) Hoelze, M. H.; Apsel, C. W.; Will, T.; Kolb, D. M. J. Electrochem. Soc. 1995, 142, 3741 .

(49) Lacconi, G. J.; Macagno, V. A. Electrochim. Acta 1994, 39, 2605. (50) Zhang, X. G.; Stimming, U. J. Electroanal. Chem. 1990, 291, 273 1166 the presence of 1,3-diethyl-2-thiourea was followed by scanning force microscopy (SFM) imaging. Surface profiles were analyzed by applying the dynamic scaling theory.

From data on $\mathrm{Cu}$ electrodeposits produced from additivefree plating baths, it can be concluded that values $\beta>0.5$ are related to the development of an unstable interface originated by the enhanced electrodeposition at negatively curved surfaces (protrusions). Then, the initial instabilities at protrusions are assisted by the development of Laplacian fields built up during the electrodeposition process. Adsorption of either the additive itself or some of its decomposition products at surface protrusions suppresses the unstable growth driving the long temporal and spatial interface evolution to that expected by the EW equation. The fulfillment of the EW equation allows us to advance a physicochemical description of $\mathrm{Cu}$ electrodeposition in the presence of organic additives.

\section{Experimental Section}

The electrodeposition of $\mathrm{Cu}$ was carried out in a conventional 3D glassmade electrochemical cell using a parallel electrode arrangement consisting of a vertically placed polycrystalline $\mathrm{Cu}$ plate cathode $\left(1 \mathrm{~cm}^{2}\right.$ area) as working electrode and a large $\mathrm{Pt}$ plate $\left(4 \mathrm{~cm}^{2}\right)$ as counter electrode. A saturated calomel electrode was used as reference. The polycrystalline $\mathrm{Cu}$ substrate was mechanically polished with alumina paste down to $0.3 \mu \mathrm{m}$ grit size, rinsed with twice-distilled water, and finally annealed at $400{ }^{\circ} \mathrm{C}$ under $\mathrm{H}_{2}$ atmosphere to obtain smooth surfaces. The aqueous plating solution which consisted of either $150 \mathrm{~g} / \mathrm{L}$ $\mathrm{CuSO}_{4} \cdot 5 \mathrm{H}_{2} \mathrm{O}+50 \mathrm{~g} / \mathrm{L} \mathrm{H}_{2} \mathrm{SO}_{4}$, or $150 \mathrm{~g} / \mathrm{L} \mathrm{CuSO}_{4} \cdot 5 \mathrm{H}_{2} \mathrm{O}+50 \mathrm{~g} / \mathrm{L}$ $\mathrm{H}_{2} \mathrm{SO}_{4}+x \mathrm{mM} 1,3$-diethyl-2-thiourea $(0<x \leq 0.4)$, was deaerated with purified $\mathrm{N}_{2}$ for $2 \mathrm{~h}$ prior to each experiment. A volume of $100 \mathrm{~cm}^{3}$ of solution was used for $\mathrm{Cu}$ electrodeposition.

The $\mathrm{Cu}$ electrodeposition was made at a constant apparent current density, $j=0.02 \mathrm{~A} \mathrm{~cm}^{-2}$ under free convection, and $T=$ $298 \mathrm{~K}$. The electrodeposition time $(t)$ was in the range $0.5 \mathrm{~min}$ $\leq t \leq 60 \mathrm{~min}$. From the steady conventional current/potential relationships ${ }^{23}$ and the value $0.05 \mathrm{~A} \mathrm{~cm}^{-2}$ for the stationary limiting current resulting from our systems, the maximum contribution of the mass transport overpotential influencing the process for $j=0.02 \mathrm{~A} \mathrm{~cm}^{-2}$ was less than $0.01 \mathrm{~V}$. This figure is considerably smaller than $0.130 \mathrm{~V}$, the cathodic potential associated with our galvanostatic experiments at $j=0.02 \mathrm{~A} \mathrm{~cm}^{-2}$. Therefore, polarization curves showed that for $j=0.02 \mathrm{~A} \mathrm{~cm}^{-2}$ $\mathrm{Cu}$ electrodeposition involves an intermediate kinetics dominated by an activation overpotential. ${ }^{24-30}$

The topography of $\mathrm{Cu}$ electrodeposits was imaged using a Nanoscope III scanning force microscope (SFM) operating in the contact mode at ambient conditions. $\mathrm{Si}_{3} \mathrm{~N}_{4}$ cantilevers were used. Typical forces were $10-30 \mathrm{nN}$. Images ranging from $0.5 \times 0.5$ $\mu \mathrm{m}^{2}$ to $20 \times 20 \mu \mathrm{m}^{2}$ were taken and analyzed using the singleimage dynamic scaling method after fitting the instrument plane and applying a subtracting procedure ${ }^{52,53}$ The best statistic scaling data are presented in this work.

\section{Results and Interpretation}

3.1. Cu Electrodeposits Produced from the Additive-free Plating Bath. SFM images $\left(20 \times 20 \mu \mathrm{m}^{2}\right)$ of $\mathrm{Cu}$ electrodeposits produced from the additive-free plating bath for the range $60 \mathrm{~s} \leq t \leq 720 \mathrm{~s}$ (Figure 1a-c) show the growth of $\mathrm{Cu}$ crystals and the progressive roughening of the interface (Figure 1d).

By measuring the size of each crystal $\left(d_{i}, i=1,2, \ldots\right.$, $N)$ and considering that

$$
\left\langle d_{\mathrm{s}}\right\rangle=(1 / N) \sum_{i=1}^{N} d_{i}
$$

(52) Vázquez, L.; Salvarezza, R. C.; Ocón, P.; Herrasti, P.; Vara, J. M.; Arvia, A. J. Appl. Surf. Sci. 1993, 70/71, 413.

(53) Krim, J.; Hevaert, I.; Haesendock, C.; Bruynseraede, Y. Phys Rev. Lett. 1993, 70, 57. 

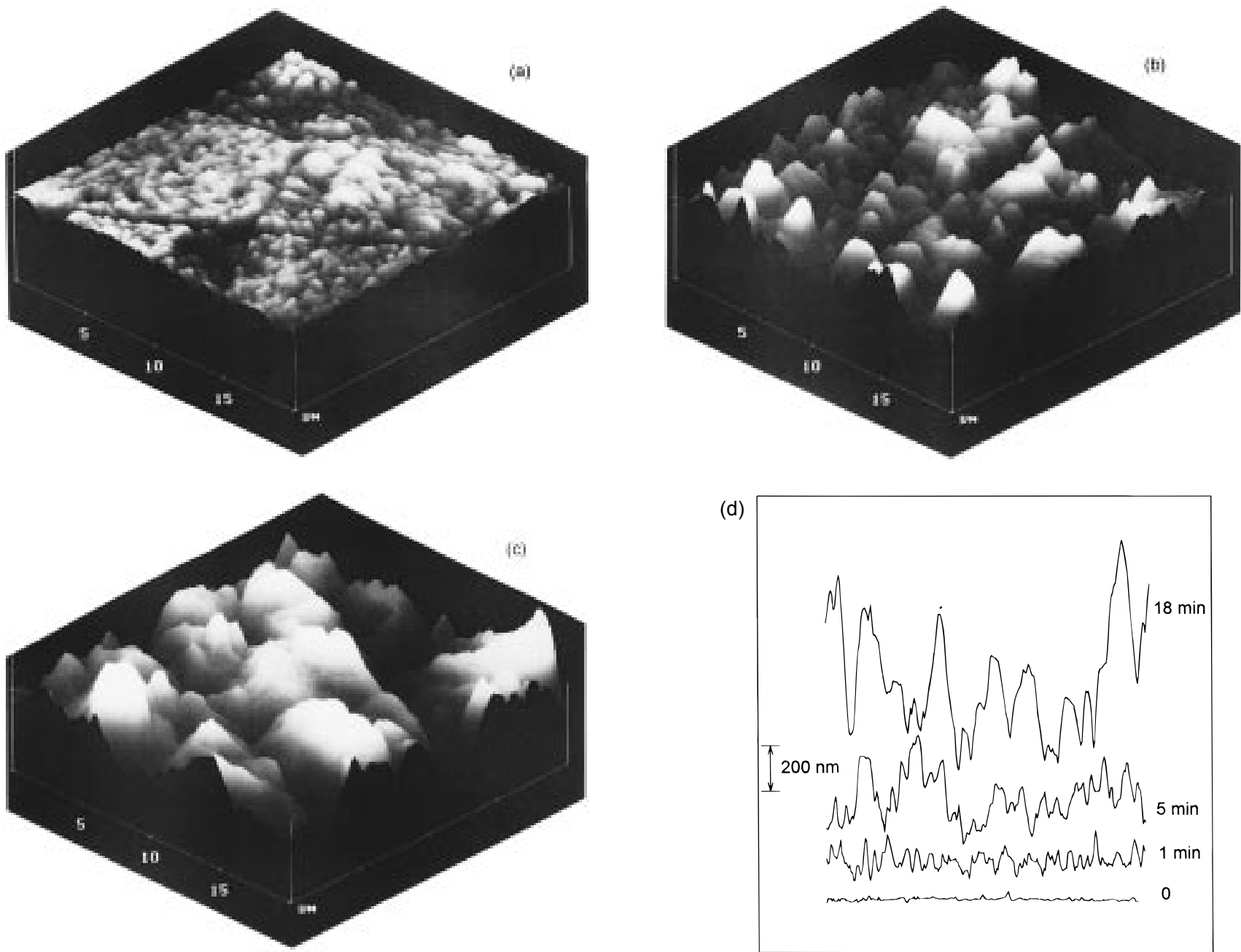

(d)

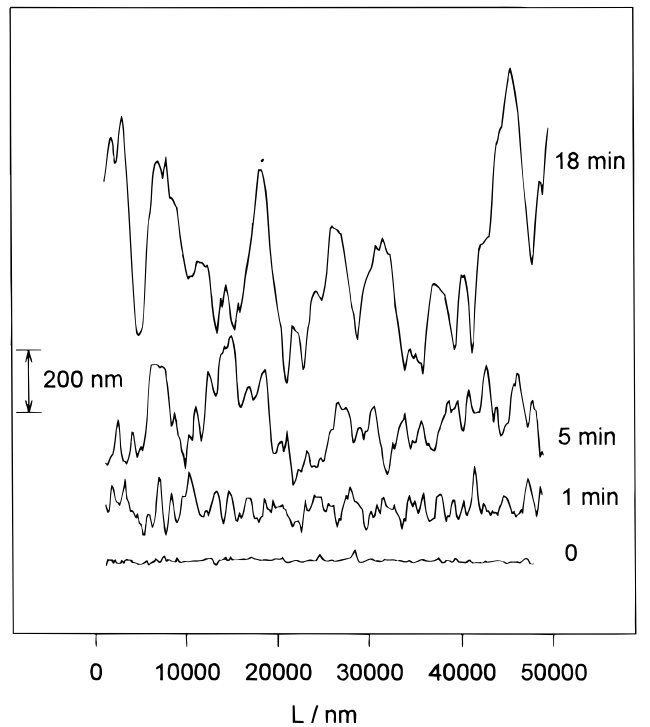

Figure 1. $20 \times 20 \mu \mathrm{m}^{2} \mathrm{SFM}$ images of $\mathrm{Cu}$ electrodeposits produced from the additive-free acid plating bath at $j=0.02 \mathrm{~A} \mathrm{~cm}^{-2}$ and $298 \mathrm{~K}$ for different electrodeposition times: (a) $t=1 \mathrm{~min}$; (b) $t=5 \mathrm{~min}$; (c) $t=12 \mathrm{~min}$. The range of $z$ is $1 \mu \mathrm{m}$. (d) Typical SFM scans obtained for $\mathrm{Cu}$ deposits at different electrodeposition times.

where $N$ is the number of crystals counted from each SFM image using appropriate software, the average crystal size $\left(\left\langle d_{s}\right\rangle\right)$ was obtained at different times $(t)$ to determine its temporal dependence. The value of $\left\langle d_{s}\right\rangle$ increases as $\left\langle d_{s}\right\rangle$ $\propto t^{1 / z}$ with $1 / z=0.70 \pm 0.06$ (Figure 2).

As $t$ is increased, the value of $W_{\mathrm{SFM}}$ for $x=0$ increases continuously without reaching a statistically steady roughness regime (Figure 3a). As mentioned in section 1.2 , the fact that no roughness saturation regime is attained allowed us to obtain only an "effective" value of $\alpha .{ }^{1}$ This value can be estimated by using the single-image dynamic scaling method, ${ }^{8,52}$ from the equation

$$
W_{\mathrm{SFM}}(t \rightarrow \infty) \propto L_{\mathrm{s}}^{\alpha}
$$

where $L_{\mathrm{s}}$ is the length of a segment measured for a SFM scan of size $S$ taken in the fast scanning direction (x).

In the range $3 \mathrm{~min} \leq t \leq 60 \mathrm{~min}$, the $\log W_{\mathrm{SFM}} \mathrm{Vs} \log$ $L_{\mathrm{s}}$ plots (Figure 4) exhibit a linear region with the slope $\alpha(I)=0.87 \pm 0.06$ and a saturation region for $\left.L_{\mathrm{s}}\right\rangle\left\langle d_{s}\right\rangle$. The extent of the linear region increases with $t$, as the value of $\left\langle d_{s}\right\rangle$ does. This indicates that the linear region corresponds to the scaling of the crystal surface itself. Correspondingly, $\alpha \cong 1$ characterizes the smooth surface of large $\mathrm{Cu}$ crystals (Figure 5).

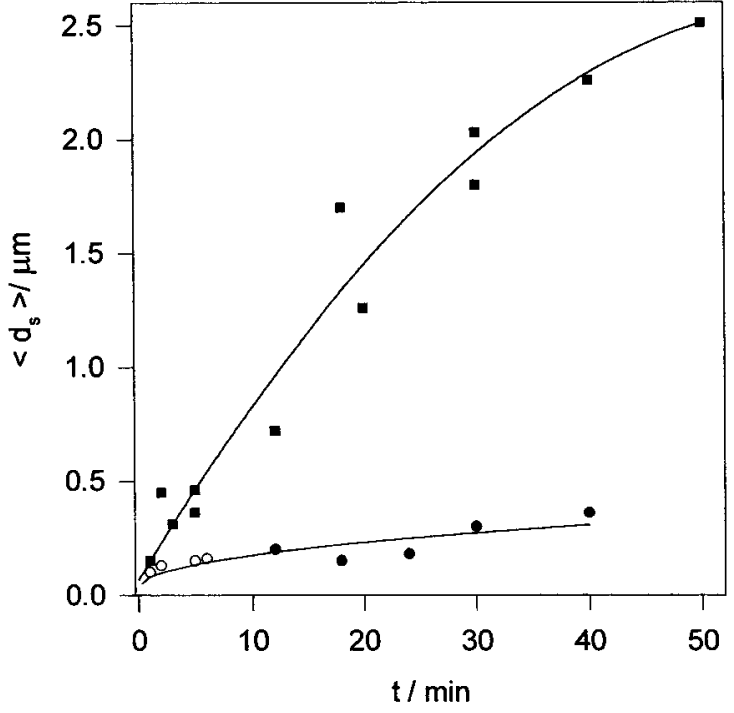

Figure 2. $\left\langle d_{s}\right\rangle$ vs $t$ plots resulting from SFM images of $\mathrm{Cu}$ electrodeposits produced from the additive-free $(\square)$ and additivecontaining $(\mathrm{O}, x=0.1 ; \bullet, x=0.3)$ acid plating baths at $j=0.02$ $\mathrm{A} \mathrm{cm}{ }^{-2}$ and $298 \mathrm{~K}$. The full traces represent the $\left\langle d_{s}\right\rangle$ vs $t^{1 / \mathrm{z}}$ equation as described in the text. 

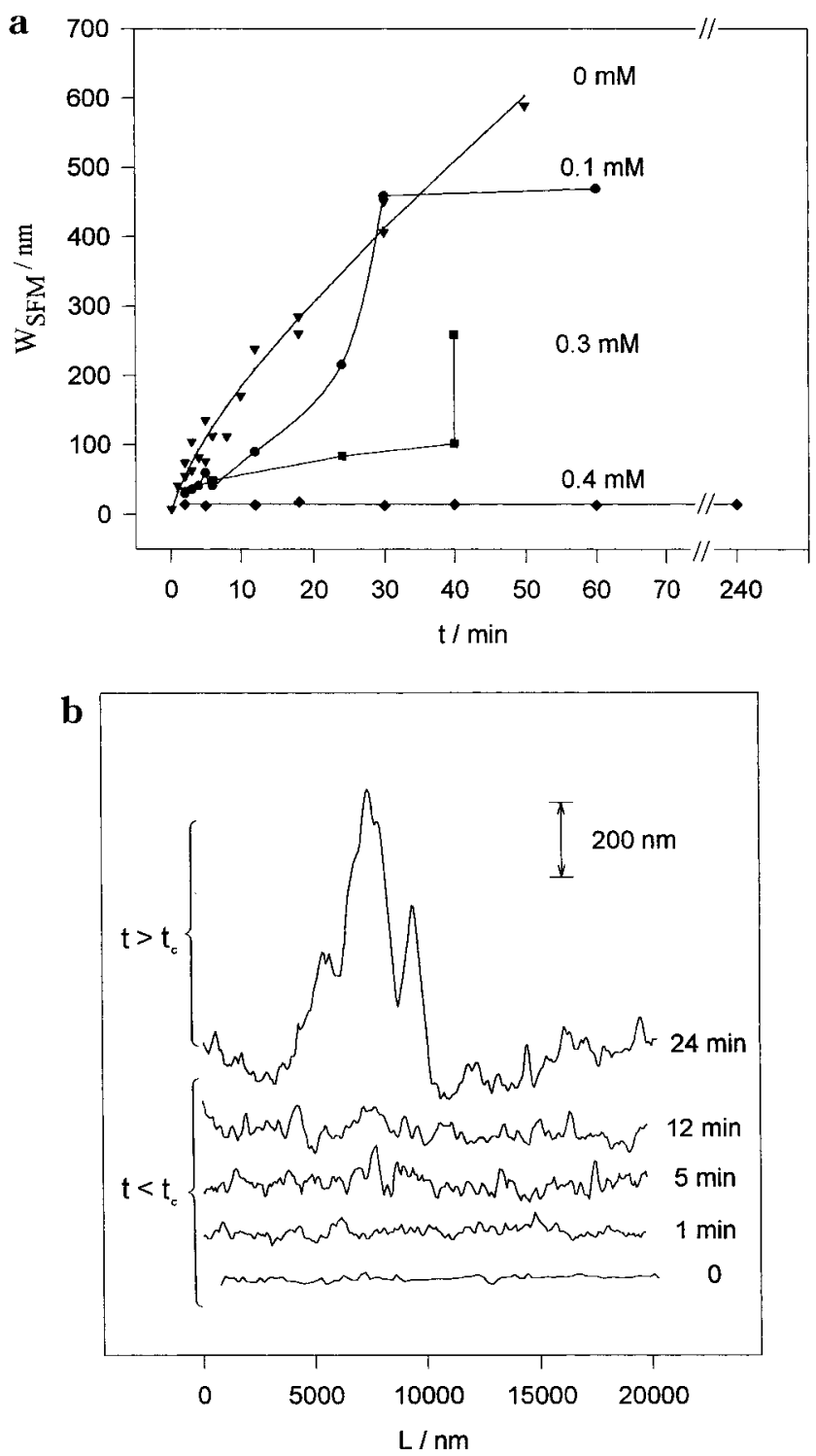

Figure 3. (a) $W_{\mathrm{SFM}}$ vs $t$ plots derived from $20 \times 20 \mu \mathrm{m}^{2} \mathrm{SFM}$ images of $\mathrm{Cu}$ electrodeposits produced from acid plating baths with different values of $x$, at $j=0.02 \mathrm{~A} \mathrm{~cm}^{-2}$ and $298 \mathrm{~K}$. (b) Typical SFM scans obtained at different electrodeposition times for a $\mathrm{Cu}$ electrodeposit produced from acid plating baths with $x=0.1$.

On the other hand, values of $\beta$ were obtained from the straight-line portion of $\log W_{\mathrm{SFM}}$ vs $\log t$ plots (Figure 6). The average slope from these plots is $\langle\beta(I)\rangle=0.63 \pm 0.08$.

3.2. Cu Electrodeposits Produced from the Additive-Containing Plating Bath. SFM images of $\mathrm{Cu}$ deposits produced from the additive-containing plating bath in the range $0.1 \leq x \leq 0.4$, for $t=24 \mathrm{~min}$ (Figure 7) show a progressive decrease in $\left\langle d_{s}\right\rangle$ as $x$ is increased. On the other hand, for either $x=0.1$ or $x=0.3,\left\langle d_{s}\right\rangle$ increases rather slowly with $t$ (Figures 2 and $8 \mathrm{a}, \mathrm{b})$. Correspondingly, from the $\log \left\langle d_{s}\right\rangle$ vs $\log t$ linear plot it results in $1 / z=0.27$ \pm 0.05 , a figure which is considerably smaller than $1 / z=$ 0.70 derived from $\mathrm{Cu}$ electrodeposits produced in the additive-free plating bath (Figure 2).

The $W_{\mathrm{SFM}}$ vs $t$ plot (Figure 3a) also indicates a slower roughening for those electrodeposits produced from additive-containing plating baths. However, for certain values of $\boldsymbol{x}$, the influence of the additive on the growth mode of the deposit becomes effective only up to a certain critical time $\left(t_{c}\right)$, afterward the roughness suppressing ability of the additive disappears. This fact, which is very

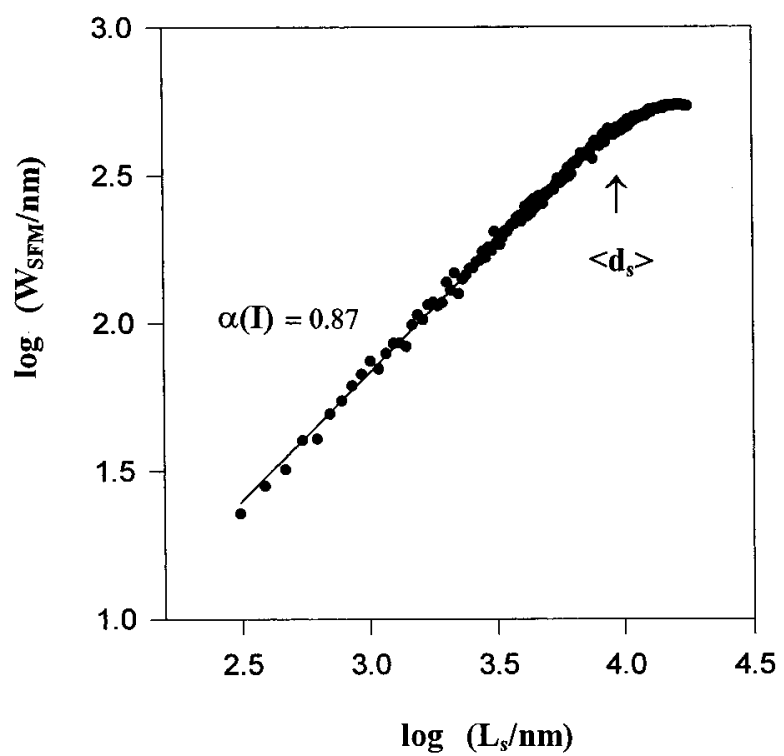

Figure 4. $\log W_{\mathrm{SFM}}$ vs $\log L_{\mathrm{s}}$ plot from the single image dynamic scaling analysis of SFM images of $\mathrm{Cu}$ electrodeposits produced from the additive-free acid plating bath at $j=0.02 \mathrm{~A} \mathrm{~cm}^{-2}$ for $t=60 \mathrm{~min}$ and $298 \mathrm{~K}$. The value of $\left\langle d_{s}\right\rangle$ is indicated by the arrow.

reproducible, is reflected by the triggering of few large $\mathrm{Cu}$ crystals for $t>t_{\mathrm{c}}$ (Figure $3 \mathrm{~b}$ ) increasing substantitally the value of $W_{\mathrm{SFM}}$. Accordingly, for $t<t_{\mathrm{c}}$ the $W_{\mathrm{SFM}}$ vs $t$ plot (Figure 3a) exhibits a clear trend to reach a limiting value of $W_{\mathrm{SFM}}$, and for $t>t_{\mathrm{c}}$ an abrupt jump in the value of $W_{\mathrm{SFM}}$ occurs (Figure $3 \mathrm{~b}$ ) attaining closely those values observed for the additive-free plating bath. The disappearance of the leveling capability of the additive can be related to several contributions such as its consumption by incorporation into the deposit, its either chemical or electrochemical decomposition, and an increase in the surface area of the deposit decreasing the additive surface concentration. The first contribution is supported by the fact that small amounts of $\mathrm{S}$ have been detected in $\mathrm{Cu}$ deposits grown in acid plating baths containing thiourea or related additives. ${ }^{39}$ The consumption of thiourea has been also measured during $\mathrm{Cu}$ electrodeposition. ${ }^{54}$

For $\mathrm{Cu}$ electrodeposits grown in the range $0.1 \leq x \leq 0.4$ for $3 \mathrm{~min}<t<t_{\mathrm{c}}$, i.e., in the range of $x$ and $t$ where $W_{\mathrm{SFM}}$ obeys a power law dependence with $t$ (Figure 3 ), the log $W_{\mathrm{SFM}}$ vs $\log L_{\mathrm{s}}$ plot (Figure 9 ) shows a linear region (I) for $L_{\mathrm{s}}<\left\langle d_{s}\right\rangle$ with the slope $\alpha(I)=0.86 \pm 0.05$, a crossover region (II) for $\left\langle d_{s}\right\rangle \leq L \leq 3 \mu \mathrm{m}$, and a region (III) for $\left.L_{\mathrm{s}}\right\rangle$ $3 \mu \mathrm{m}$ with $W_{\mathrm{SFM}}$ increasing very slowly with $L_{\mathrm{s}}$. In region III, which is more clearly defined for $x=0.4$, the spatial evolution of $W_{\mathrm{SFM}}$ fulfills the $W_{\mathrm{SFM}}$ vs $\left(\log L_{\mathrm{S}}\right)^{0.5}$ dependence (Figure 10a,b), as predicted by the EW equation.,17

The value of $\beta$ for region $\mathrm{I}$, which corresponds to the scaling of a single-crystal surface, can be estimated from $1 / z=0.27 \pm 0.05$ (Figure 2, $x=0.3, x=0.1$ ) and $\alpha(I)=$ $0.86 \pm 0.05$ (Figure 9). It results in $\beta(I)=0.24 \pm 0.05$.

The roughening kinetics in region III was determined from $5 \times 5 \mu \mathrm{m}^{2}$ and $20 \times 20 \mu \mathrm{m}^{2}$ SFM imaging data, i.e., for $L_{\mathrm{s}}>3 \mu \mathrm{m}$. For $0.1 \leq x<0.3$, the time dependence of $W_{\mathrm{SFM}}$ fits the prediction of the EW equation for $\mathrm{t} \rightarrow 0^{18}$ as a $W_{\text {SFM }}$ vs $(\log t)^{0.5}$ relationship is obeyed (Figure 11$)$. For $x \geq 0.4, W_{\mathrm{SFM}}$ becomes independent of $t$ (Figure 4 ) so that $\beta=0$, in agreement with the prediction of the EW equation for $t \rightarrow \infty$. This behavior was verified in the range $1 \mathrm{~min}$ $\leq t \leq 240 \mathrm{~min}$.

(54) Johnson, G. R.; Turner, D. R. J. Electrochem. Soc. 1962, 109, 798 


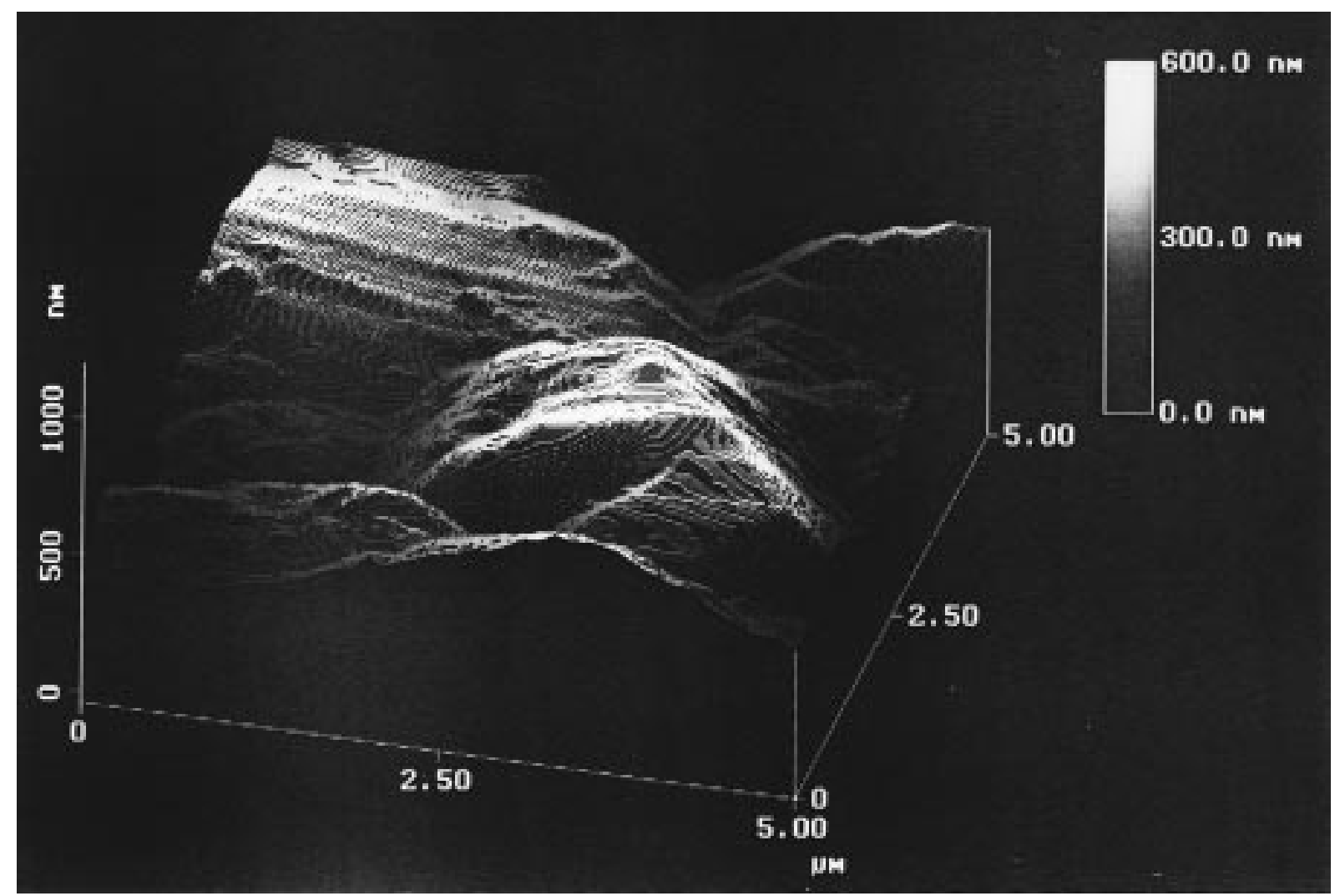

Figure 5. SFM topography $\left(5 \times 5 \mu \mathrm{m}^{2}\right)$ of a large $\mathrm{Cu}$ single crystal produced from the additive-free plating solution for $t=24$ min. Steps and terrace domains can be clearly observed.

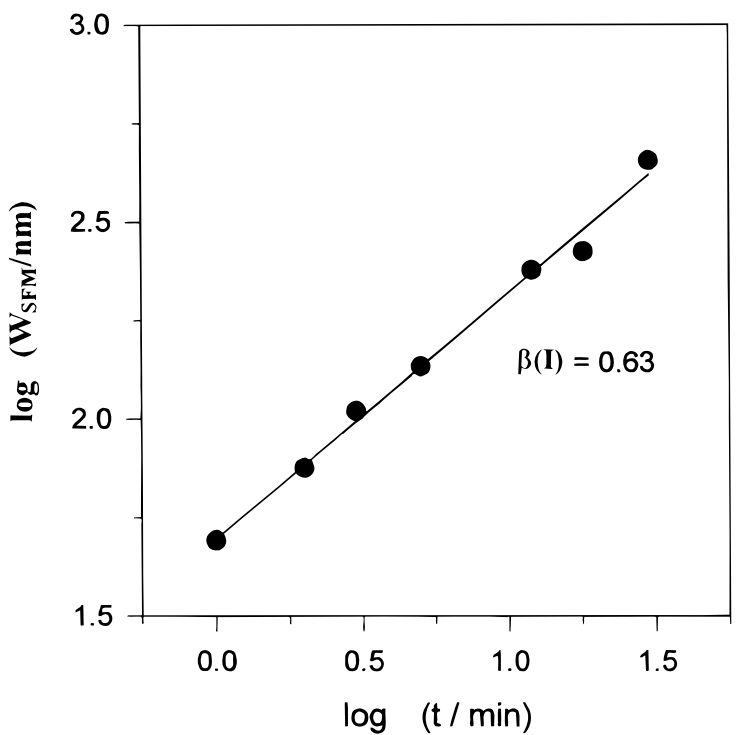

Figure 6. $\log W_{\mathrm{SFM}}$ vs $\log t$ plot from $20 \times 20 \mu \mathrm{m}^{2}$ SFM images of $\mathrm{Cu}$ electrodeposits produced from the additive-free acid plating bath at $j=0.02 \mathrm{~A} \mathrm{~cm}^{-2}$ and $298 \mathrm{~K}$.

\section{Discussion}

4.1. Growth Modes of $\mathrm{Cu}$ Electrodeposits in the Additive-free Acid Bath. For the additive-free bath, the value of $\alpha(I)=0.87 \pm 0.05$ appears to be consistent with growth models incorporating surface diffusion, although the relatively high value $\beta(I)=0.63 \pm 0.08$ exceeds the expected initial value which for this type of growth should be in the range $0.20 \leq \beta \leq 0.25 .{ }^{14-16}$ The value $\beta(I)=0.63 \pm 0.08$ resulting from data covering practically 2 decades in electrodeposition time is closer to $\beta \cong 0.5^{7}$ and greater than $\beta \cong 0.11$ obtained for $\mathrm{Cu}$ electrodeposition on $\mathrm{Au}(111)$ at $j=8 \times 10^{-4} \mathrm{~A} \mathrm{~cm}^{-2} .^{22}$ The set of values $\alpha \approx 1$ and $\beta=0.11$ reported in ref 22 is difficult to explain in terms of growth models available at present.

The unstable growth regime related to $\beta>0.5^{1}$ may result from different contributions such as (i) the presence of a Laplacian field assisting $\mathrm{Cu}$ growth at protrusions normal to the deposit surface, ${ }^{7}$ (ii) a shadowing effect among growing crystals ${ }^{1}$, (iii) the presence of a spatial or correlated noise, ${ }^{4,55}$ and (iv) the existence of energy barriers at step edges (Schwoebel barrier) hindering interlayer mass transport. 1,56

The existence of a Schwoebel barrier has been related to $\beta=0.56$, a figure determined for $\mathrm{Cu}$ deposits grown by molecular beam epitaxis, ${ }^{21}$ but for a polycrystalline metal phase, as in the case of our work, the existence of a Schwoebel-type energy barrier at step edges has been questioned. ${ }^{57}$ This conclusion appears to be further sustained by recent three-dimensional Monte Carlo simulations for the growth of solids with step edge barriers leading to $0.11 \leq 1 / Z \leq 0.40,{ }^{58}$ i.e., values of $1 / z$ well below 0.70 .

The presence of spatially and temporally correlated noise in growth models would increase the value of $\alpha$ and $\beta$, as discussed in refs 4 and 55 . The origin of these correlations in electrochemical deposition is far from proven, and for the consideration of their possible influence on the mechanism of the process, further experimental work and modeling are required.

Recent results for three-dimensional off-lattice Monte Carlo simulations for the growth of a polycrystalline film including geometric shadowing and surface diffusion have

(55) Amar, J.; Lam, P.-M.; Family, F. Phys. Rev. A 1991, 43, 4548 (56) Schwoebel, R. L. J. Appl. Phys. 1968, 40, 614.

(57) Jeffries, J. H.; Zuo, J. K.; Creig, M. M. Phys. Rev. Lett. 1996, 76 4931 .

(58) Smilauer, P.; Vvedenski, D. D. Phys. Rev. B 1995, 52, 14263. 

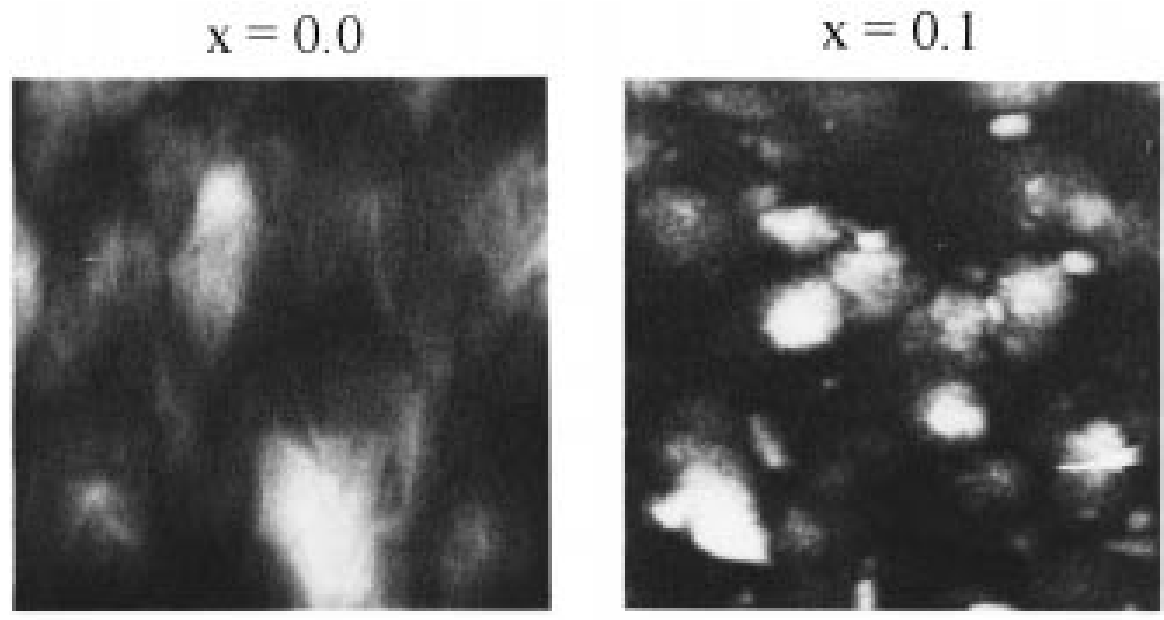

$\mathrm{x}=0.3$

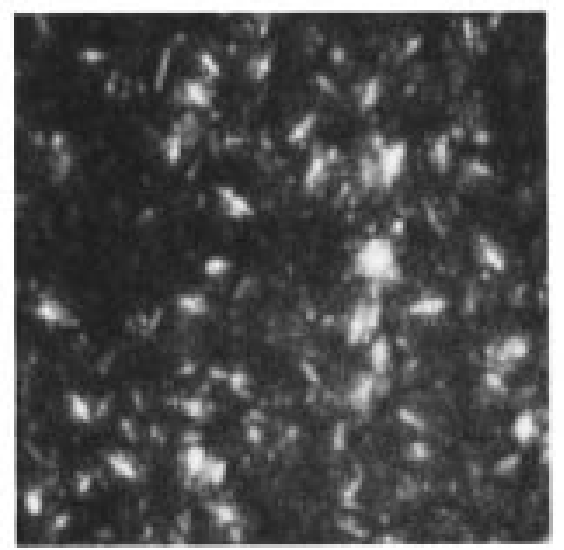

$\mathrm{x}=0.4$

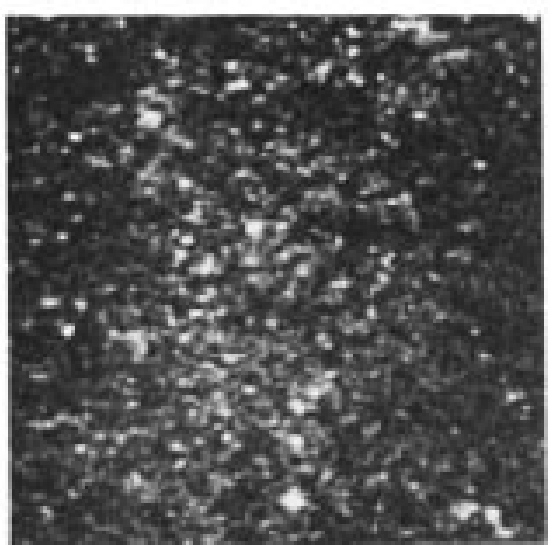

Figure 7. $20 \times 20 \mu \mathrm{m}^{2} \mathrm{SFM}$ images of $\mathrm{Cu}$ electrodeposits resulting from different acid plating baths at $t=24 \mathrm{~min}$ for $j=0.02$ $\mathrm{A} \mathrm{\textrm {cm } ^ { - 2 }}$ and $298 \mathrm{~K}$.

led to values of $1 / z$ in the range $0.25 \leq 1 / z \leq 0.50 .^{59}$ This range of figures is far from $z=0.7$ as observed in our experimental system.

From the preceding analysis for $\mathrm{Cu}$ electrodeposition, explanations $\mathrm{ii}-\mathrm{iv}$ as the origin of the unstable front can, in principle, be discarded. Therefore, in our case the unstable front could be related to the presence of a Laplacian field. In fact, two-dimensional Monte Carlo simulations for viscous fingering in the marginally stable flow regime have led to $\alpha=0.89$ and $\beta=0.66,{ }^{60}$ these figures being close to our exponents for $\mathrm{Cu}$ electrodeposits in the three-dimensional space. This comparison, however, is of a limited value and the coincidence of figures may be fortituous. In principle, the growth model developed for chemical vapor deposition ${ }^{61}$ in the surface reaction-controlled regime might be applicable to understand the origin of a grained interface and the development of a stable finger, but no explicit values of $\alpha$ and $\beta$ can be found for this model. Furthermore, the appearance of stable fingers, as predicted by this model, was not observed for our systems at least up to $t$ $=480$ min. $^{62}$ From the discussion above it can be concluded that there is no satisfactory explanation based upon models for unstable growth available at present.

(59) Albano, E.; Salvarezza, R. C.; Arvia, A. J. In preparation.

(60) Ferer, M.; Smith, D. H. Phys. Rev. E 1994, 49, 4114.

(61) Bales, G. S.; Redfield, A. C.; Zangwill, A. Phys. Rev. Lett. 1989, 62,776 .

(62) Mendez, S.; Schilardi, P.; Salvarezza, R. C.; Arvia, A. J. Submitted.
The presence of Laplacian fields could be related to electric and concentration fields simultaneously built up during the electrodeposition process. However, the unstable behavior of the growth front appears from the very early stages of the process at the nanometer level (Figure 3a), i.e., temporal and spatial scales where the appearance of instabilities assisted by those Laplacian fields become rather unlikely. Therefore, it is reasonable to admit that the origin of the unstable front observed at the short time range would result from a lower electrodeposition overpotential for a negatively curved surface rather than for a flat one, an effect referred to as capillarity. ${ }^{63,64}$ Therefore, when protusions are formed they can grow faster than valleys triggering the unstable growth front which is further sustained by the nonuniform electric field ${ }^{64}$ and/ or concentration field created around the growing deposit. In fact, capillarity has been invoked to explain the origin of dendritic growth, ${ }^{63}$ a problem which is usually mapped into Laplacian fronts.

4.2. Growth Modes of $\mathrm{Cu}$ Electrodeposits in the Additive-Containing Acid Bath. The dynamics of the mobile interface in additive-containing plating baths and $t<t_{\mathrm{c}}$ is characterized by regions I, II, and III. Region I, which also in this case corresponds to the scaling of crystal surfaces, exhibits $\alpha(I)=0.86 \pm 0.06$ and $\beta(I)=0.24 \pm$ 0.05 , these figures being close to $0.66 \leq \alpha \leq 1$ and 0.20

(63) Despic, A. R.; Popov, K. I. In Modern Aspects of Electrochemistry Bockris, J. O'M., Conway, B. E., Eds.; Butterworths: New York, 1972 ; Vol. 7, Chapter 4, p 199.

(64) Barkey, D. P.; Muller, R. H.; Tobias, C. W. J. Electrochem. Soc 1989, 136, 2207. 


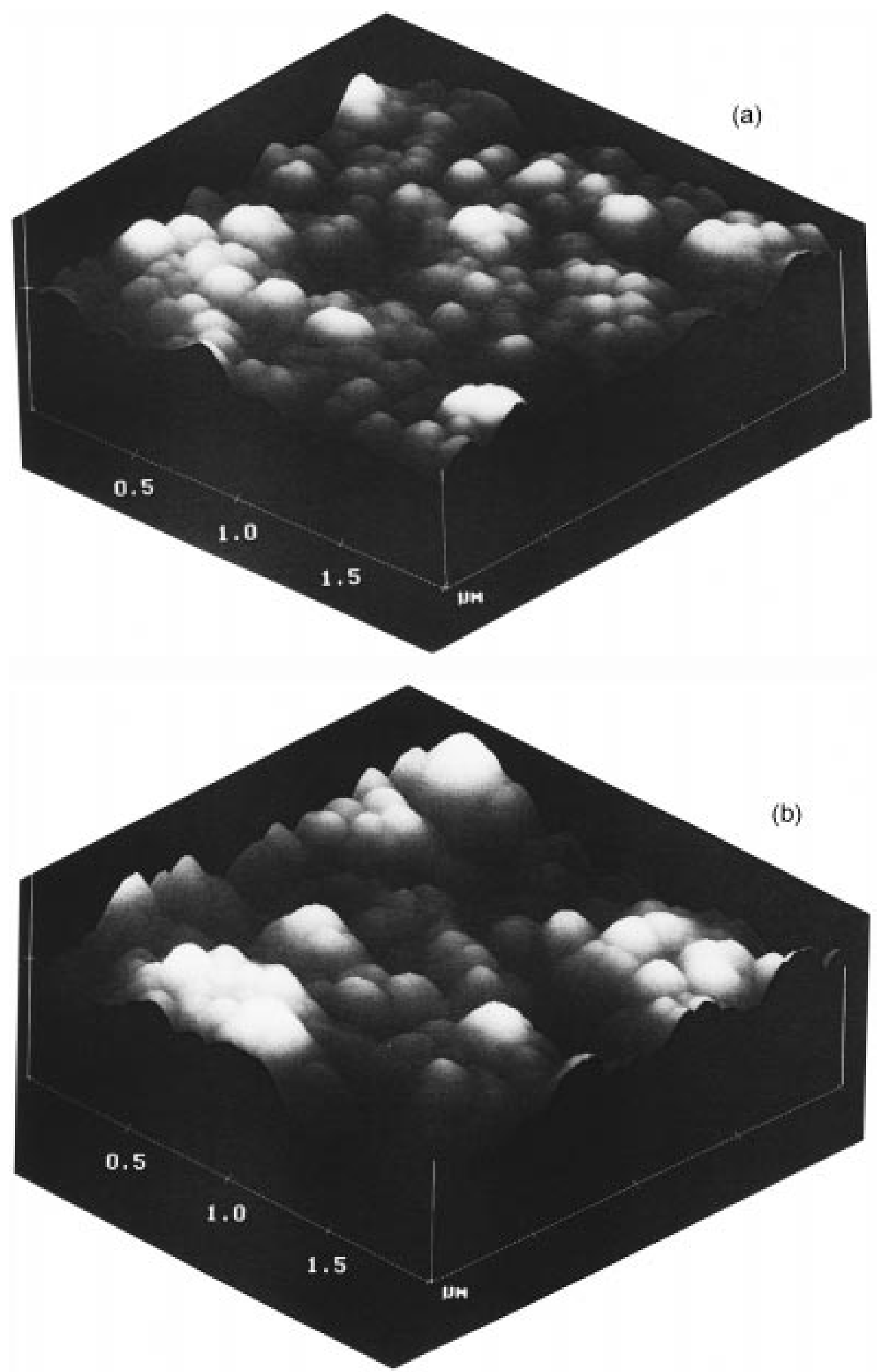

Figure 8. $2 \times 2 \mu \mathrm{m}^{2} \mathrm{SFM}$ images of $\mathrm{Cu}$ electrodeposits resulting from the additive-containing acid plating bath $x=0.3$ for $j=$ $0.02 \mathrm{~A} \mathrm{~cm}^{-2}$ and $298 \mathrm{~K}$ : (a) $t=1 \mathrm{~min}$; (b) $t=12 \mathrm{~min}$. The $z$ range is $0.2 \mu \mathrm{m}$.

$\leq \beta \leq 0.25$ resulting from solid growth models including surface diffusion relaxation driven by curvature effects. ${ }^{14-16}$ Results in region I can be directly compared to $\alpha=0.87$ \pm 0.06 and $\beta=0.63 \pm 0.08$ obtained in the additive-free plating bath. Therefore, it is clear that the additive reduces markedly the instabilities observed in the additive free plating bath driving the crystal surface to a growth mode including surface diffusion as the main relaxation mechanism. However, it is well-known that thiourea adsorption, as well as other organic molecules adsorbed 


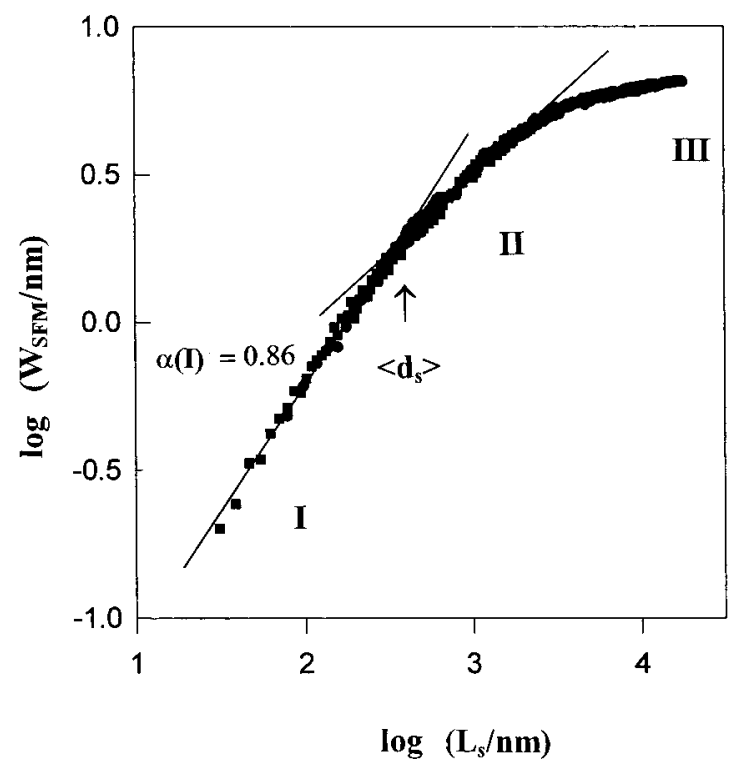

Figure 9. $\log W_{\mathrm{SFM}}$ vs $\log L_{\mathrm{s}}$ plot derived from the single image dynamic scaling analysis of SFM images of $\mathrm{Cu}$ electrodeposits produced from the additive-containing acid plating bath, $x=$ 0.3 , at $j=0.02 \mathrm{~A} \mathrm{~cm}^{-2} 298 \mathrm{~K}, t=24 \mathrm{~min}$. The three regions described in the text are indicated by I, II, and III.

at the metal/electrolyte interface, reduces the surface diffusion coefficient of metal atoms and, accordingly the diffusion length (I). ${ }^{65}$ This picture is consistent with the fact that $\left\langle d_{s}\right\rangle$, an 1 -dependent parameter, is drastically diminished when the additive is present in the bath for $x>X_{c}$.

If additive molecules reduced surface diffusion of $\mathrm{Cu}$ atoms, then additive molecules would enhance rather than suppress instabilities promoting 3D growth, as occurs when either a Schwoebel barrier at step edges or a "jail" effect at terraces is present. As this is not the case, both contributions can be neglected as important physical processes determining the interface evolution of $\mathrm{Cu}$ electrodeposits, as already discussed in section 4.1.

Let us try to find an explanation why the presence of additive species reduces $\mathrm{Cu}$ atom surface mobility, whereas the interface seemingly behaves as expected for growth models including surface diffusion for $L_{\mathrm{s}}<d_{\mathrm{s}}$. In fact, the influence of surface diffusion on the interface evolution of $\mathrm{Cu}$ electrodeposits in the presence of thiourea has been concluded from the initial part of the $\log W_{\mathrm{SFM}} \mathrm{Vs} \log L_{\mathrm{s}}$ and $\log W_{\mathrm{SFM}}$ vs $\log t$ plots. ${ }^{22}$ Extensive computer simulations of ballistic models including surface diffusion have shown that roughness exponents become independent of $l$ for $l>0 .{ }^{60}$ In fact, only when $l=0$, roughness exponents change to those expected from the KPZ model. Certainly, organic adsorbates diminish the value of 1 , but the mobility of $\mathrm{Cu}$ atoms is far from suppressed.

As referred to above, for the additive-containing plating bath, region II should be considered as a crossover region between regions I and III extending from $\left\langle d_{s}\right\rangle$ to $L_{\mathrm{s}} \cong 3 \mu \mathrm{m}$ where the EW behavior is observed. It is interesting to note that the early temporal dependence $W_{\mathrm{SFM}} \propto(\log t)^{0.5}$ predicted by the EW equation is only observed at low values of $x$, whereas for $x \geq 0.4$ only the long time prediction of this equation, i.e., $\beta=0$, can be determined.

The validity of the EW equation for the asymptotic temporal and spatial limits to describe a complex process such as the interface evolution for Cu electrodeposition in

(65) Alonso, C.; Salvarezza, R. C.; Vara, J. M.; Arvia, A. J. Electrochim. Acta 1990, 35, 1331.
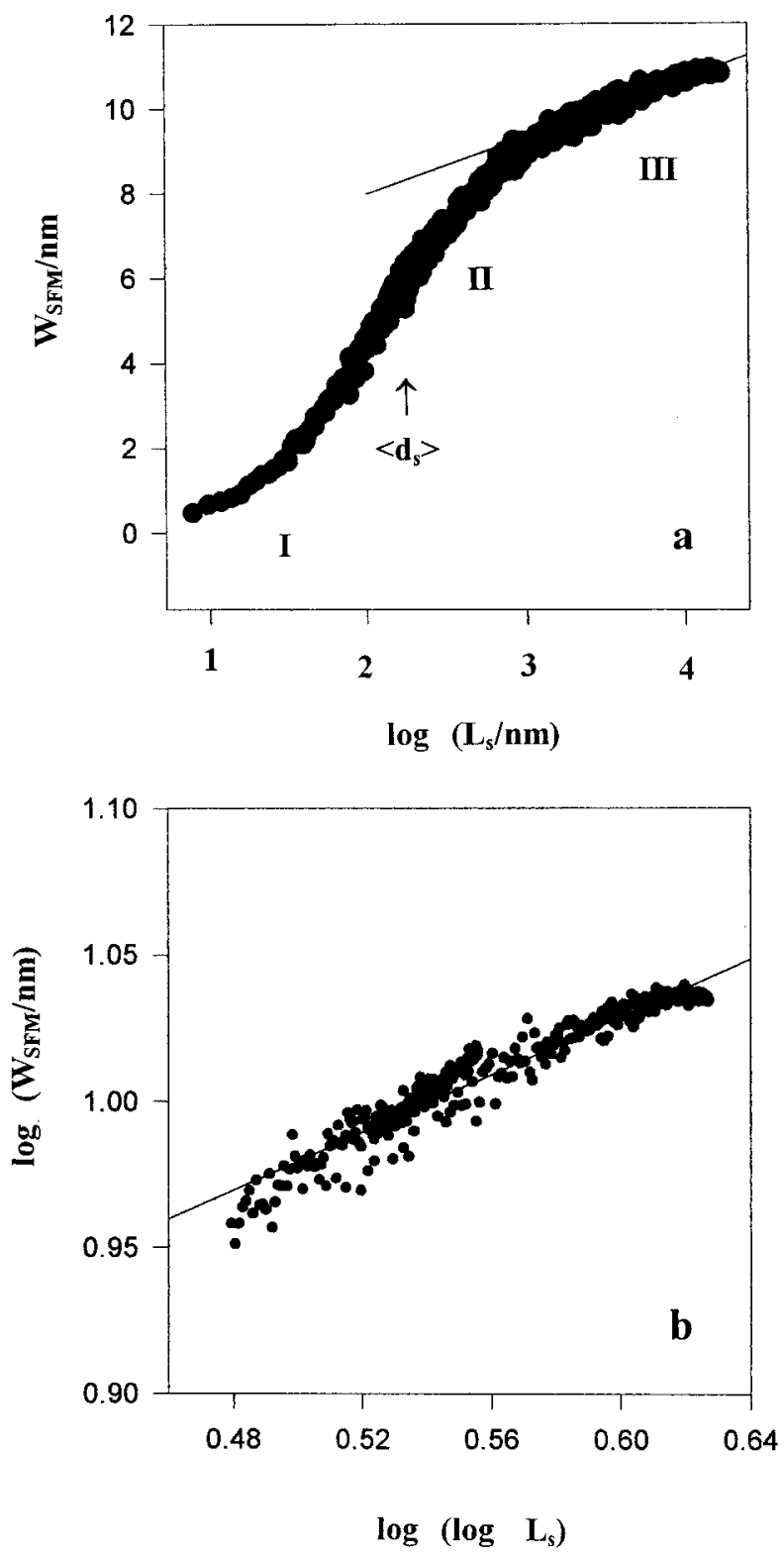

Figure 10. (a) $W_{\mathrm{SFM}}$ vs $\log L_{\mathrm{s}}$ plot derived from the dynamic scaling analysis of SFM images of $\mathrm{Cu}$ electrodeposits produced from the additive-containing acid plating bath, $x=0.4$, at $j=$ $0.02 \mathrm{~A} \mathrm{~cm}^{-2}$ for $t=60 \mathrm{~min}$ and $298 \mathrm{~K}$. (b) $\log W_{\mathrm{SFM}} \mathrm{Vs} \log (\log$ $L_{\mathrm{s}}$ ) plot resulting from data shown in (a) for region III. The straight line represents the prediction of the EW model.

the presence of an organic additive is, in principle, unexpected and it deserves further discussion. The main characteristic of this model is the enhanced flux of the arriving material at valleys which results in a leveling of surface roughness.

For $\mathrm{Cu}$ electrodeposition in the presence of the organic additive, the validity of the EW equation for $L_{\mathrm{s}}>3 \mu \mathrm{m}$ can be approached as follows. At $j=0.02 \mathrm{~A} \mathrm{~cm}^{-2}, \mathrm{Cu}$ is deposited at a rate equivalent to 60 monolayers $\mathrm{s}^{-1}$, so that the S-containing molecules, which adsorb strongly on metal surface but are present in a relatively small number in the bulk solution, are preferentially adsorbed at negatively curved surfaces (protrusions). This results in a nonhomogeneous distribution of adsorbates on the $\mathrm{Cu}$ surface. Moreover, the higher additive molecule coverage at protrusions slows down the rate of chargetransfer reaction from the $\mathrm{Cu}^{2+}$ ions to $\mathrm{Cu}$. This hindrance to the charge-transfer process may be either partial or complete, depending on the degree of surface coverage 


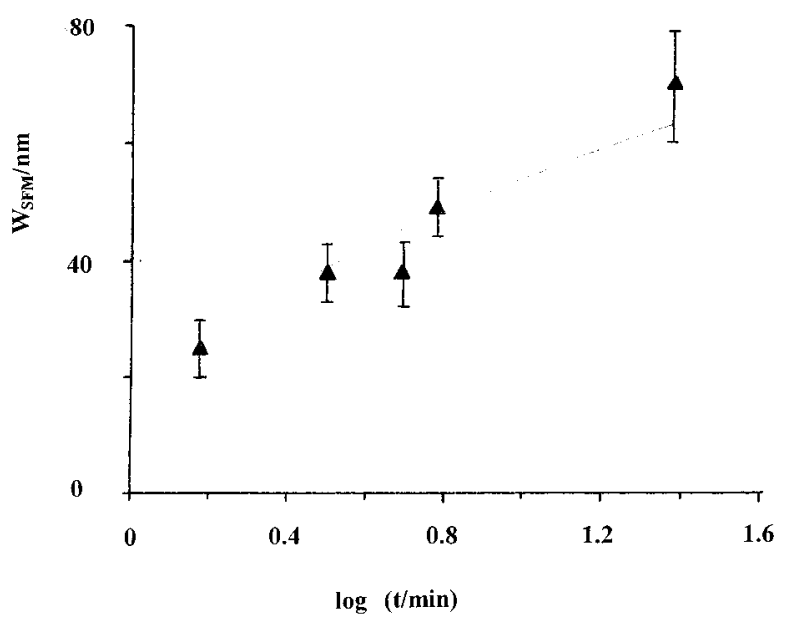

Figure 11. $W_{\mathrm{SFM}}$ vs $\log t$ plot from $20 \times 20 \mu \mathrm{m}^{2}$ SFM images of $\mathrm{Cu}$ electrodeposits produced from the additive-containing acid plating bath at $j=0.02 \mathrm{~A} \mathrm{~cm}^{-2}$. The solid line corresponds to the $W_{\mathrm{SFM}} \propto(\log t)^{0.5}$ fit.

and nature of the additive molecule, as determined for charge-transfer redox reactions on thiol-covered $\mathrm{Au}$, where the inhibition effect increases with the length of the alkyl chain of thiol molecules. ${ }^{6}$ Hence, the presence of the additive preferentially adsorbed at negatively curved domains of the $\mathrm{Cu}$ surface would be favoring the electrodeposition of $\mathrm{Cu}$ at positively curved surfaces (valleys) and flat domains where the degree of surface coverage by additive molecules is lower than at protrusion. Accordingly, a leveling effect is produced, which mimics the behavior of the EW equation. Otherwise, once protrusions approach flatness, the electric field decreases there and the adsorbate layer attains a more uniform distribution. Therefore, from the standpoint of this work, the EW behavior has not been observed in ref 22 presumably because in this case the spatial analysis of the surface roughness has been restricted to small scale lengths.

Finally, within the framework of the preceding scenario, the failure of the additive to suppress unstable growth can be related to the fact that below $x_{\mathrm{c}}$ the degree of surface coverage by additive molecules at certain protrusions becomes insufficient to decrease the rate of the chargetransfer reaction from the $\mathrm{Cu}^{2+}$ ions to $\mathrm{Cu}$. The decrease in the value of $x$ below $x_{c}$ could be due in part to the additive incorporation into the growing deposit and in part to the

(66) Sabatini, E.; Rubinstein, I. J. Phys. Chem. 1987, 91, 6663. own increase in the effective area of the deposit. Then, when the condition $\boldsymbol{x}<\boldsymbol{x}_{\mathrm{c}}$ is reached, the high $\mathrm{Cu}^{2+}$ electrodeposition local current density at partially covered or bare protrusion domains triggers $\mathrm{Cu}$ deposit growth preferentially there, and correspondingly, the surface roughness jumps suddenly from the steady-state regime to the unstable one.

\section{Conclusions}

From the preceding analysis the following relevant contributions involved in the interface motion of $\mathrm{Cu}$ electrodeposits either in the presence or in the absence of additives can be advanced.

(i) $\mathrm{Cu}$ electrodeposition in the absence of organic additives results in an unstable interface composed of by large crystals. Enhanced deposition at negatively curved surfaces appears to be the microscopic origin of protrusion development. An inhomogeneous electric field and/or concentration field assist further growth of instabilities.

(ii) Unstable growth is suppressed by the preferential adsorption of either the additive molecules or some of their decomposition products on protrusion domains hindering the discharge of the $\mathrm{Cu}^{2+}$ there and favoring a net flux of depositing $\mathrm{Cu}$ at valleys producing a leveling effect.

(iii) The validity of the EW model to describe the interface evolution on the asymptotic limit is a new and quantitative support to the mechanism of the additive indicated in (ii).

(iv) There is critical threshold concentration of the additive which is necessary to suppress the unstable growth. This critical concentration should be related to a critical degree of surface coverage by additive molecules required to hinder $\mathrm{Cu}$ electrodeposition at protrusion domains.

(v) The adsorption of additive molecules diminishes the surface mobility of $\mathrm{Cu}$ atoms leading to the formation of small $\mathrm{Cu}$ crystals. Restricted surface diffusion of $\mathrm{Cu}$ adatoms driven by curvature effects appears to be the main surface relaxation mechanism governing the interface evolution inside $\mathrm{Cu}$ crystals.

Acknowledgment. This work was financially supported by the Consejo Nacional de Investigaciones Científicas y Técnicas of Argentina (CONICET) and Fundación Antorchas. S.M. and M.F. thank Proyecto FONDECYT (Chile) for financial support (Proyects No. 2950054 and 1971244).

\section{LA970362T}

